\title{
Calculation of Water Wheel Design Parameters for Micro Hydroelectric Power Station
}

\author{
Dilshod Kodirov ${ }^{1}$ and Obid Tursunov ${ }^{1,2^{*}}$ \\ ${ }^{1}$ Department of Power Supply and Renewable Energy Sources, Tashkent Institute of Irrigation and \\ Agricultural Mechanization Engineers, 100000 Tashkent, Uzbekistan \\ ${ }^{2}$ Green Energy and Environment Laboratory, National Laboratory Astana, Nazarbayev University, \\ 010000 Astana, Kazakhstan
}

\begin{abstract}
This paper is devoted to the issues such as modelling the design parameters and operating modes and improving the design of micro hydroelectric power plants operating in low-pressure water flow. Taking into consideration above-mentioned issues, it is possible to increase the efficiency of using low-pressure water energy systems. The main dimensions of the water wheel of a micro hydropower plant depend on the water flow velocity $v$, water volume $Q$, acting at a fixed point in time on the water wheel blade, and also on the depth of the water level $H$.
\end{abstract}

\section{Introduction}

The use of unconventional and renewable energy sources, energy efficiency of hydrocarbon fuels and stabilization of the ecological balance in energy practice are scientific research of great importance in the world. In this regard, the long-term national energy programs of developed countries have set the goal to achieve the share of renewable energy sources by at least $20 \%$ [1]. In world practice, micro-hydroelectric power stations are being intensively commissioned for energy supply, which are among the priority representatives of renewable energy sources, and special attention is paid to the development of this field of research $[2,3]$.

All over the world, special attention is paid to application of reliable and environmentally friendly technologies in power generation. In this industry, in particular, a main priority over others are given for the modelling of micro-hydropower plants operating working and design parameters in low-pressure watercourses, improving structures in general and developing effective technologies used in low-pressure watercourse systems [4, $5,6]$.

Despite significant progress in this direction, the problem of improving energy- and resource-saving micro-hydroelectric power stations for low-pressure watercourses and the development of simple structures of this device has not been sufficiently studied [7, 8, 9, $10,11,12,13]$. This paper discusses the optimization problems for the water wheel modelling and design parameters of micro-hydro power plants operating in a low-pressure watercourse, based on mathematical modelling of the water-wheel operating mode. A theoretical study was conducted to improve the energy efficiency of micro-hydro power plants, and on the basis of the results of these studies, a solution was proposed for

\footnotetext{
Corresponding authors: obidtursunov@gmail.com
} 
developing a compact, reliable, cost-effective micro hydro power plant for low-pressure watercourses.

\section{Research Methods}

The basic water wheel size of a micro-hydroelectric power station depends on the water flow speed, water volume $Q$ acting in a fixed point in time on the water wheel blade, and the depth of the water level $H$. A review of the literature shows $[15,16,17]$ that in order to ensure the efficiency and compactness of the water wheel, its external diameter must be chosen as follows $D \geq 2 H$ [18]. The depth of the water wheel, i.e. differences of external and internal diameters, is determined by the formula found with empirical method:

Figures and tables, as originals of good quality and well contrasted, are to be in their final form, ready for reproduction, pasted in the appropriate place in the text. Try to ensure that the size of the text in your figures is approximately the same size as the main text (10 point). Try to ensure that lines are no thinner than 0.25 point.

$$
\delta=k \sqrt[3]{\frac{D}{H}},
$$

where $0,4 \leq k \leq 0,5$ - water flow coefficient on the water wheel blade. A water wheel width is defined by the formula:

$$
B=\frac{Q}{v k \delta}
$$

The area of the water wheel blades can be determined using the formula below:

$$
S=\delta B\left[1+\frac{\cos 2 \alpha}{\sin \alpha}\right]
$$

where $\alpha$ - angle of the blades from the water level, (a width of the blades is same as a width of the water wheel $B$ ). The angle $\alpha$ is the main parameter of water wheel. The value of this angle must be chosen in such a way that the current water force on the blade is maximum when the blade is entering in the water and the minimum when leaving it:

$$
\alpha=180^{\circ}-\arcsin \left(\frac{D-2 l}{D}\right),
$$

where $l$ blade length:

$$
l=\sqrt{B^{2}+\delta^{2}}
$$

Now, we find a water mass at a fixed point in time, that is, the mass of water that is in the "pocket" of the water wheel. The value of the water mass acting on the water wheel blade is variable, since when the "pocket" moves along the water flow, this mass takes on a different value, therefore it is determined by the following differential equation:

$$
\frac{d m}{d t}=\rho S(v-\bar{v})
$$

where $\rho$ - water density, $\bar{v}$ - water velocity after acting on blades. A process of turbulence occurs when the foot moves in the water flow, therefore a water velocity $\bar{v}$ is different from the normal speed $v$, т.e. $\bar{v}=c v, 0<c<1$. The angular velocity of the water wheel is directly dependent on linear speeds $\bar{v}$, i.e.: 


$$
w=4 v /[D(1+\cos \theta / \sin \alpha)]=\bar{v} \frac{D}{2} .
$$

A resultant force on the water wheel blades is also variable and is determined by the following differential equation:

$$
F=\frac{d}{d t}(m(v-\bar{v}))=\rho S v^{2}\left(1-c^{2}\right) .
$$

From the physical point of view, in order to determine the force (7) acting on the water blade, it is necessary to determine a "pulling force" $F_{p}$ and a force of gravity $F_{t}$.

A pulling force $F_{p}$ and gravity foce $F_{t}$ is determined with following formula:

$$
F_{P}=\mu \frac{\rho}{2} \bar{v}^{2} S, F_{t}=\eta \frac{\rho}{2} \bar{v}^{2} S
$$

where $\mu, \eta$ - coefficient of proportionality. The forces that are defined with formula (8) are vector quantities, so the resultant force $F$ can be represented as the addition of two vectors (see Fig.1).

$$
F=\sqrt{F_{p}^{2}+F_{t}^{2}}
$$

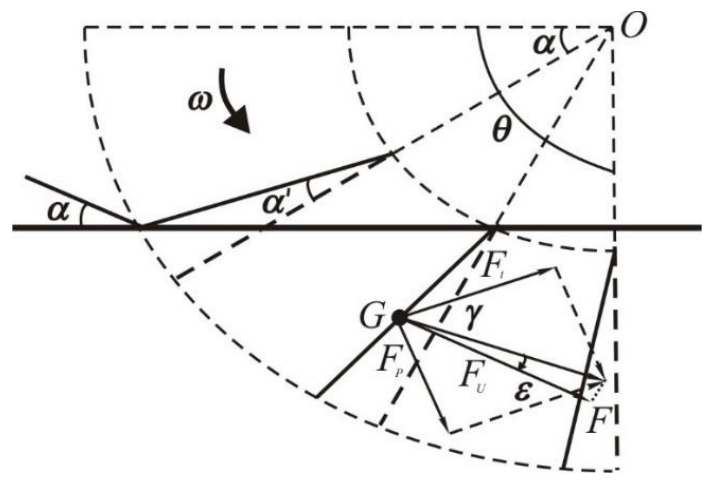

Fig.1. Forces acting on the water wheel blades

Hence, the useful force acting at an angle $\varepsilon$ :

$$
F_{u}=F \cos \varepsilon,
$$

where $\varepsilon=\arctan \frac{\mu}{\eta}-(\alpha-\gamma)$.

In order to ensure a mathematical model adequacy with a real process, we study the law of rotational motion of the water wheel. The water wheel blade is denoted as $X_{i}, i=1,2, \ldots, n$, where $n$ - number of blades. Supposing that the water wheel blades is a rotating body around a fixed axis $O z$ with angular velocities $w$, defined using formula (6), according to the kinetic moment change theorem, we have: 


$$
\frac{d K}{d t}=X_{1}\left(F_{u}\right)+X_{2}\left(F_{u}\right)+\cdots+X_{n}\left(F_{u}\right)=\sum_{i=1}^{n} X_{i}\left(F_{u}\right) .
$$

A kinetic moment of a rigid body rotating around a fixed axis $O z$ is determined by the formula:

$$
K=I_{z} w
$$

where $I_{z}$ - inertia moment of the mechanical system in a fixed point in time relative to the axis of rotation $O_{z}$, it is determined using the formula below:

$$
I_{z}=m_{1} r^{2}+m_{2} r^{2}+\cdots+m_{n} r^{2}=\sum_{k=1}^{n} m_{k} r^{2}
$$

Taking into consideration the formula (11), a differential equation (10) can be written as below:

$$
I_{z} \frac{d w}{d t}=\sum_{i=1}^{n} X_{i}\left(F_{u}\right)
$$

It is known from the solid bodies kinematics, that

$$
w=\frac{d \theta}{d t}=\dot{\theta},
$$

where $\theta$-rotation angle of the water wheel blades relative to the axis $O z$.

Consequently, we have:

$$
I_{z} \frac{d w}{d t}=I_{z} \frac{d^{2} \theta}{d t}=\sum_{i=1}^{n} X_{i}\left(F_{u}\right)
$$

Expression (12) is called as differential equation of the rotational motion of a rigid body around a fixed axis. In the equation, the moment of inertia $I_{z}$ is an analogue of mass $m$, which determines by equation (5) $\frac{d^{2} \theta}{d t}-$ linear acceleration, $\sum_{i=1}^{n} X_{i}\left(F_{u}\right)$ - is the main vector of acting forces $F_{u}$.

Several forces act on the water wheel blades which are determined by the formula (9), therefore, $R_{1}$ and $R_{2}$ reactions emerges in the bearings of the water wheel axis under the action of forces $F_{u}=\sum_{k=1}^{n} F_{u}^{k} \cdot\left\{F_{u}^{1}, F_{u}^{2}, \ldots, F_{u}^{n}\right\}$, these reactions are also external forces, but their moment relative the axis $O z$ is zero. Therefore, in the differential equation (12) we can ignore these forces.

The differential equation (12) allows solving the following two problems of the dynamics of body motion:

1. Determine the moment of the acting forces relative to the axis of rotation for a given rotation law $\theta=f(t)$ and the moment of inertia $I_{z}$ relative to the axis of rotation.

2. Under given initial conditions $t=t_{0}, \theta=f\left(t_{0}\right)$ and the moments of acting forces relative to the axis of rotation is determined by the law of rotational motion $\theta=f(t)$. 
Now we will find work on rotating the water wheel blade. Supposing that the force on the water wheel blade $X_{i}, i=1,2, \ldots, n$, is acted upon by the force $F_{u}$, which is determined using formulas (9), at an angle $\alpha$. The work of this force is equal to the work done to rotate the water wheel blade. When the blades rotate $X_{i}$ at a sufficiently small angle $d \theta$, the blade passes the $\operatorname{road} d s=r d \theta$, where the outer radius $r=\frac{D}{2}$ of the water wheel. Therefore, the perfect work is determined by the differential equation:

$$
d A=F_{u} \cdot r \cdot \sin \alpha d \theta
$$

Considering the moment of force (12) relative to the axis, the rotation is equal to $K=F_{u} r \sin \alpha$, then

$$
d A=K d \theta
$$

Integrating both sides of Eq. (13), we find that the work performed by water-wheel blades during rotation at the final angle $d \theta$ is the integral sums of the elementary works, i.e.

$$
A=\int_{\theta_{1}}^{\theta_{2}} K \mathrm{~d} \theta
$$

It means that the work during water wheel blade rotational movement is equal to multiplying the value of the acting forces moments by the value of the angle of rotation.

The power of the water wheel is estimated by the perfect work of the acting forces in a unit of time, in other words, it can be said that power is a speed of the work:

$$
P=\lim _{\Delta t \rightarrow 0} \frac{\Delta A}{\Delta t}=\frac{d A}{d t}
$$

Thus, we find the equation for the water wheel power:

$$
P=\frac{d A}{d t}=\frac{K\left(F_{u}\right) d \theta}{d t}=K\left(F_{u}\right) w
$$

This means that the water wheel power is equal to the multiplication of the acting forces by the angular velocity. It is known from theoretical mechanics that according to the differential equation (7) the water wheel power is determined using the formulas:

$$
P=\rho S_{c m} v^{3} c(1-c)^{2}
$$

It should be emphasized that the area of the water-wheel blade, which intersects with water at an angle $\alpha$, is also variable, more precisely, this area of the blade increases when the blade enters the water, and decreases when it leaves. A square of this area with angle $\alpha$ dependence is determined using the following formula found by the engineering method:

$$
\begin{gathered}
S_{c m}=\frac{\left(1-\frac{B}{r} \cdot \frac{1}{\sin \alpha}\right)}{\left(1-\frac{B}{r}\right)} S \\
\Psi=\frac{\left(1-\frac{B}{r} \cdot \frac{1}{\sin \alpha}\right)}{\left(1-\frac{B}{r}\right)}
\end{gathered}
$$


We find the average value by calculating the following definite

$$
\begin{aligned}
& \Psi_{u r}=\frac{1}{\frac{3 \pi}{2}-\alpha} \int_{\alpha}^{\frac{3 \pi}{2}} \frac{1-\frac{B}{r} \cdot \frac{1}{\sin \alpha}}{1-\frac{B}{r}} d \tau=\frac{1}{\frac{3 \pi}{2}-\alpha}\left[\int_{\alpha}^{\frac{3 \pi}{2}} \frac{1}{1-\frac{B}{r}} d \tau-\int_{\alpha}^{\frac{3 \pi}{2}} \frac{\frac{B}{r}}{1-\frac{B}{r}} \frac{d \tau}{\sin \tau}\right]= \\
& =\frac{1}{1-\frac{B}{r}}-\left.\frac{\frac{B}{r}}{1-\frac{B}{r}} \ln \operatorname{tg} \frac{\tau}{2}\right|_{\alpha} ^{\frac{3 \pi}{2}}=\frac{1}{1-\frac{B}{r}}\left(1-\frac{B}{r} \ln \mid \operatorname{tg} \frac{\tau}{2} \|_{\alpha}^{\frac{3 \pi}{2}}\right) \text {. }
\end{aligned}
$$

\section{Results and Discussions}

Considering the formula (15), we give the approximate values of the area depending on the angle in the following table 1.

Table 1. Values of the area depending on the angle

\begin{tabular}{|c|c|c|c|c|c|c|}
\hline$\alpha$ & $16^{\circ}$ & $32^{\circ}$ & $48^{\circ}$ & $64^{\circ}$ & $80^{\circ}$ & $96^{\circ}$ \\
\hline$S_{c m}, m^{2}$ & 0,18 & 0,37 & 0,54 & 0,62 & 0,74 & 0,8 \\
\hline
\end{tabular}

If the water level $1 \mathcal{M}$, then we choose the water wheel diameter with a length of $2 \mathcal{M}$. Consequently, on the basis of formulas (1) - (3), the depth of the water wheel $\approx 0,509_{\mathcal{M}}$, the width $\approx 0,799 M$ and according to formula (4), blade enters the water under angle $\approx 16$.

An accepted water density is $\approx 1000 \frac{\kappa 2}{\mathcal{M}^{3}}$. From the above equations $(6,14$ and 15$)$, the following approximate values of the angular velocity of rotation and the values of power $P$ depending on the linear velocity $v$ value of water are presented in Table 2.

Table 2. Angular speed $w$ of rotation, power values $P$ depending on the linear velocity value $v$ of

\begin{tabular}{|c|c|c|c|c|c|}
\hline$v, v / s$ & 2 & 2,3 & 2,3 & 2,7 & 3 \\
\hline$w$, turn/min & 76,42 & 87,8 & 95,4 & 103,2 & 114,6 \\
\hline$P, \mathrm{~J} / \mathrm{s}$ & 4608 & 7010 & 9000 & 11340 & 15552 \\
\hline
\end{tabular}

If the velocity of the water flow $v=2 M / c$ and water acts on the water wheel blade at an angle $\alpha=16^{\circ}$, then according to table 2, the water wheel rotates with angular velocities $w \approx 76 a \check{u} /$ мuн . As emphasized above, when the water wheel is rotated, the area $S_{c m}$ that intersects with water takes on different values. Depending on these values, we present the approximate power values in the following table 3:

Table 3. Water wheel calculations based on the mathematical model

\begin{tabular}{|l|c|c|c|c|c|c|}
\hline$S_{c m}, m^{2}$ & 0,18 & 0,37 & 0,54 & 0,62 & 0,74 & 0,8 \\
\hline$P, \mathrm{~J} / \mathrm{s}$ & 4608 & 9472 & 13824 & 15872 & 18432 & 2048 \\
\hline
\end{tabular}


From the table we find the average power value $P \approx 13781$ Дж / . These calculations are useful when choosing a generator that converts mechanical energy into electrical.

The results of the water wheel calculations made on the basis of the following mathematical model are summarized in Table. 3

Table 4. The water wheel micro hydroelectric power station dimensions

\begin{tabular}{|l|l|l|}
\hline$№$ & Parameter Names & Sizes, $\mathrm{mm}$ \\
\hline 1 & External diameter & $2000 \pm 3,7$ \\
\hline 2 & Internal diameter & $1000 \pm 2,3$ \\
\hline 3 & Internal part of blade & $509,44 \pm 0,875$ \\
\hline 4 & External part of blade & $799 \pm 1$ \\
\hline 5 & Blade numbers & 12 pc. \\
\hline 6 & Pulley diameter & 350 \\
\hline
\end{tabular}

Based on the specific dimensions of the water wheel given in Table 4, the functional diagram of a water wheel operating in a low-pressure watercourse has the form below (see Fig. 2).

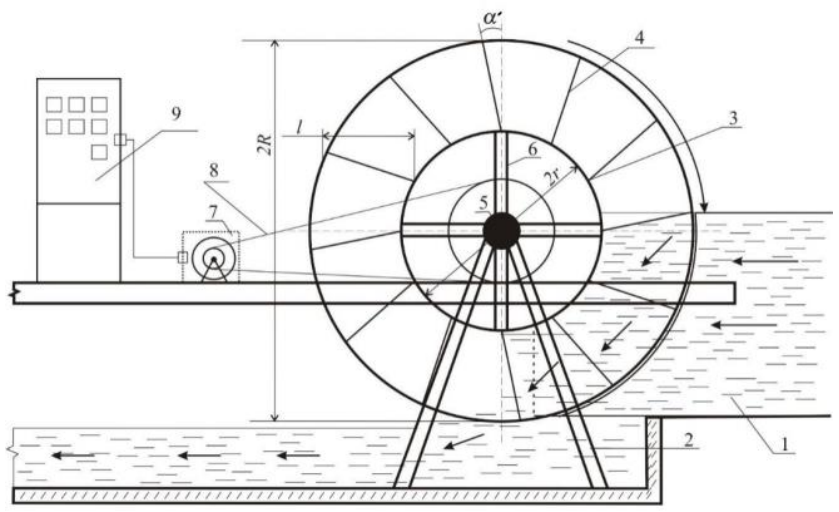

Fig. 2. Functional diagram of a micro-hydro power plant for low-pressure watercourses: 1- water flow; 2 - frame installation; 3 - housing; 4- blades; 5- shaft; 6 - steel core; 7 - generator; 8 - belt drive; 9 - electric power observation unit; $\alpha^{\prime}$ - rational angle

On the basis of the functional scheme (see Fig. 2), a laboratory model of a microhydroelectric power station was developed for testing the operating modes under laboratory conditions (see Fig. 3).

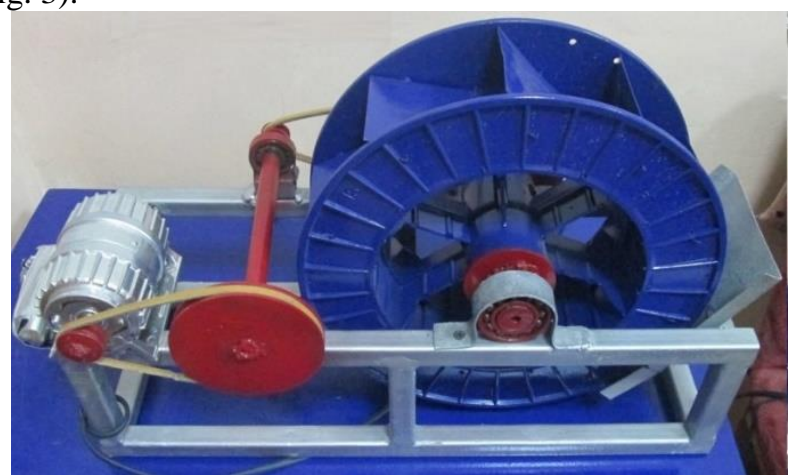

Fig. 3. Laboratory model of micro hydroelectric power station 
The results of testing micro hydroelectric power station in laboratory mode are given in Table. 5 .

Table 5. The results of testing micro hydroelectric power station in laboratory mode

\begin{tabular}{|c|c|c|c|c|}
\hline $\begin{array}{c}\text { Observation } \\
\text { numbers }\end{array}$ & $\begin{array}{c}\text { Blade angel, } \\
\text { grad. }\end{array}$ & $\begin{array}{c}\text { Current } \\
\text { force, } \\
\mathrm{A}\end{array}$ & Voltage, V & Power, Wt \\
\hline 1 & 5 & 0,18 & 212 & 38,16 \\
\hline 2 & 10 & 0,20 & 218 & 43,6 \\
\hline 3 & 15 & 0,22 & 221 & 48,62 \\
\hline 4 & 20 & 0,19 & 215 & 40,85 \\
\hline 5 & 25 & 0,19 & 215 & 40,85 \\
\hline 6 & 30 & 0,17 & 212 & 36,04 \\
\hline 7 & 35 & 0,16 & 210 & 33,60 \\
\hline
\end{tabular}

Table 5 shows the test results of micro-hydroelectric power plants when changing the blades angle of the water wheel to the water surface area of $5 \div 35^{\circ}$. When tested, the measurement device showed that the generated electrical energy has the following indicators: voltage up to $210 \div 221 \mathrm{~V}$, current force up to $0.16 \div 0.22 \mathrm{~A}$. Observations were shown that when the blades are located at an angle to the water surface $\alpha=15^{\circ}$, the generator connected with a water wheel, produces electrical energy above $0.22 \mathrm{~A}$, and the voltage is a value close to the standard $221 \mathrm{~V}$. Thus, this angle value of the blades provides the action of forces, at the entrance-maximum, and at the exit-minimum. The angle determined by the theoretical method $\left(\alpha=16^{\circ}\right)$ turned out to be close to the experimentally found value.

The developed micro-hydroelectric power station is installed in a low-pressure watercourse (see Fig.4a), where a hydraulic facility is built to control the water flow (see Fig.4b).

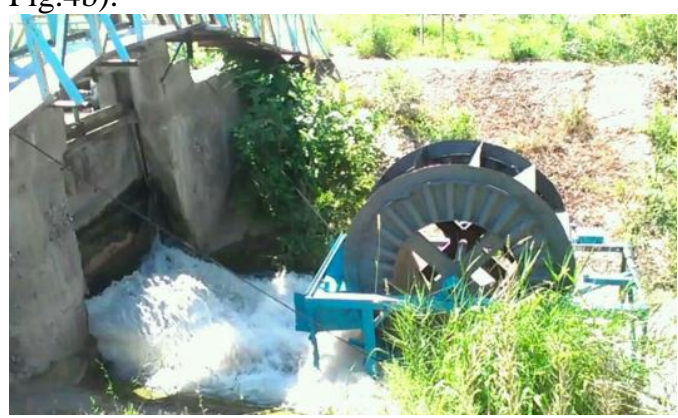

a)

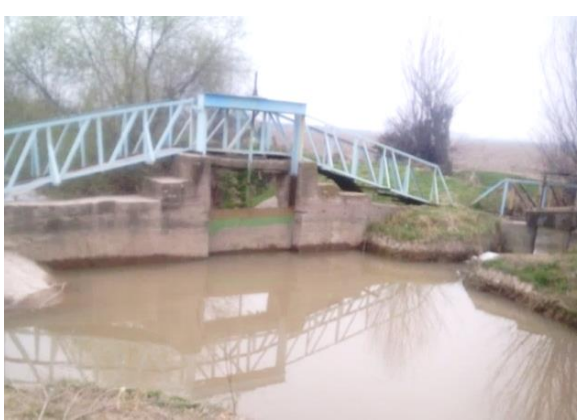

b)

Fig. 4. External image of the installed water wheel (a) and hydraulic structures for controlling the water flow (b)

To test microhydroelectric power station, a water wheel connected to a generator using a belt drive was put into operation. The test results of the micro-hydroelectric power station are given in table. 6 
Table 6. The test results of micro hydroelectric power station

\begin{tabular}{|c|c|c|c|}
\hline \multirow{2}{*}{ Observation numbers } & $\begin{array}{c}\text { Current force, } \\
\mathrm{A}\end{array}$ & Voltage, $\mathrm{V}$ & Power, $\mathrm{kWt}$ \\
\hline 1 & 40,4 & 200 & 8,8 \\
\hline 2 & 41,9 & 234 & 9,8 \\
\hline 3 & 46,3 & 224 & 10,4 \\
\hline 4 & 44,45 & 207 & 9,2 \\
\hline 5 & 45,3 & 210 & 9,6 \\
\hline 6 & 40,19 & 214 & 8,6 \\
\hline
\end{tabular}

While studying the quality indicators of the generated electric energy of a microhydroelectric power station operating in a low-pressure watercourse, attention was paid to two main parameters: Voltage $(\mathrm{V}) ; 2$. Frequency of voltages $(\mathrm{Hz})$.

The obtained results were compared with the values given in the normative documents of the international standard.

Work on the measurement was carried out in three periods of time. During the research, the device AR.5 was used. The results obtained are analyzed using Power vision programs (see Fig. 5, 6, 7).

\begin{tabular}{|c|c|}
\hline & 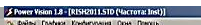 \\
\hline E⿵冂卄 & 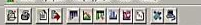 \\
\hline प्र由 & प्र圂 \\
\hline
\end{tabular}

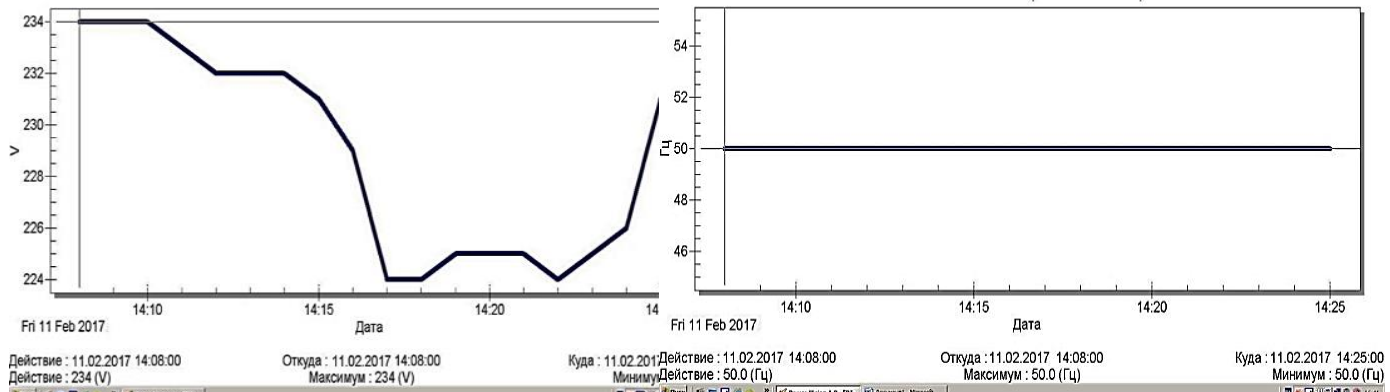

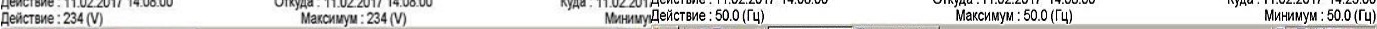

a)

b)

Fig. 5. The change in ac voltage (a) and frequency (b) in the time interval (from 14:08 to 14:25)
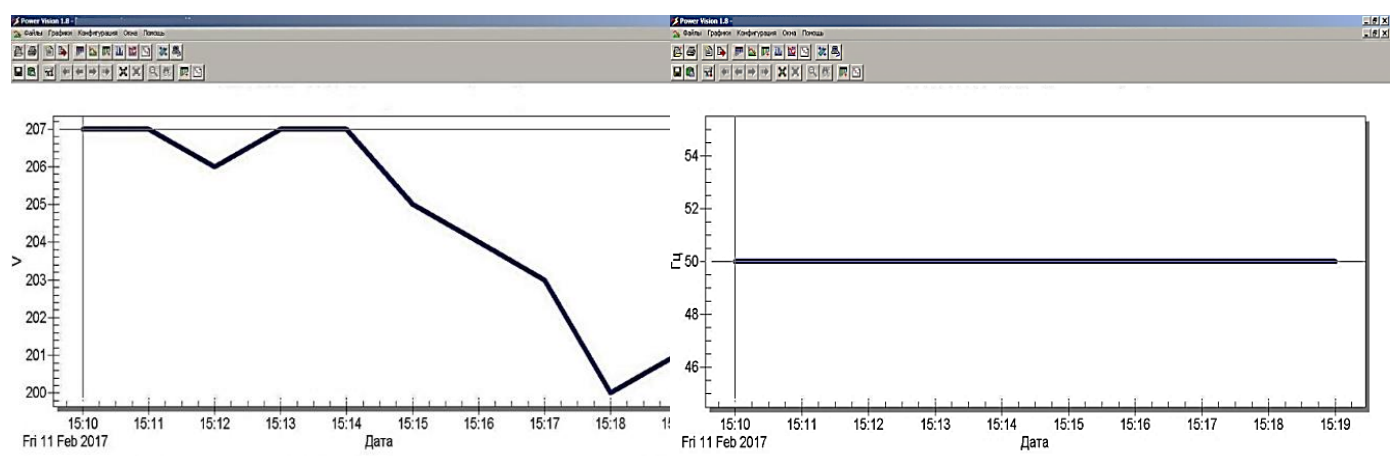

Действие : 11.02 .2017 15:10:00

a)

b)

Fig. 6. The change in ac voltage (a) and frequency (b) in the time interval (from 15:10 to 15:19) 


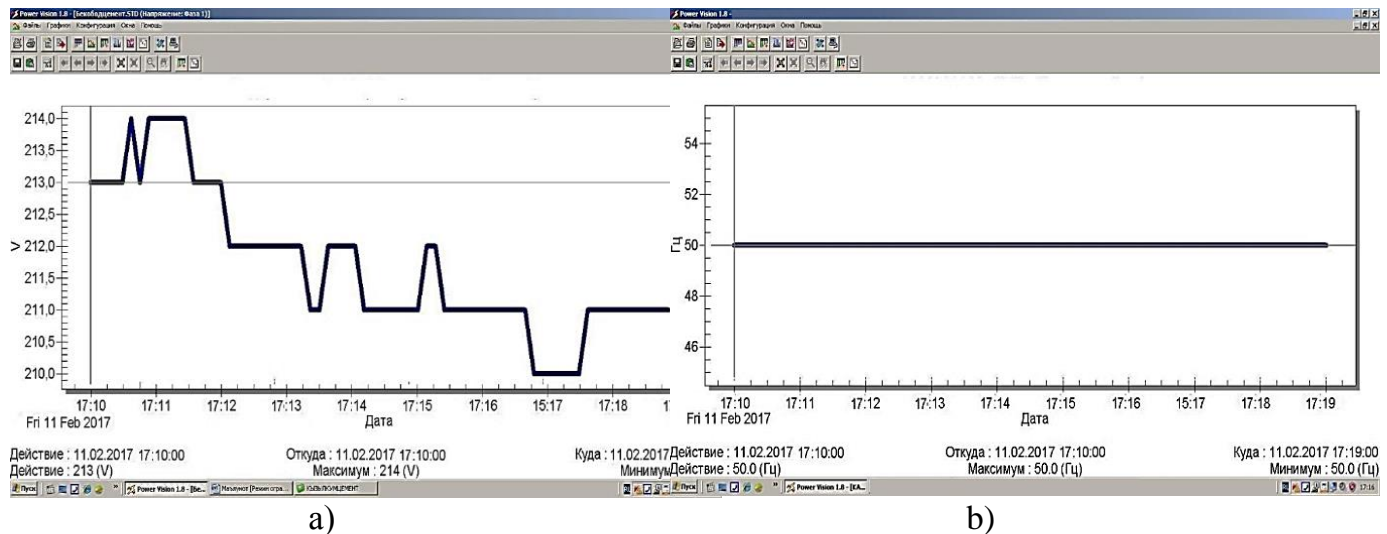

Fig. 7. The change in ac voltage (a) and frequency (b) in the time interval (from 17:10 to 17:19)

Figures 5, 6, 7 show the alternating voltage wave obtained from the research. Here you can see that the maximum voltage is 234 volts, the minimum voltage is 200 volts, and the average voltage is 217 volts. According to the normative documents of the international standard, the boundary voltage is $\pm 10 \%$ (198-242 volts). Thus, the voltage value satisfies all the requirements of the regulatory act.

During the research investigations, the frequency value was 50 Hertz and did not change. In the normative documents of the international standard, the frequency of the alternating voltage is 50 Hertz. Thus, the frequency value satisfies all the requirements of the regulatory document.

\section{Conclusions}

Summarizing the research results, we can draw the following conclusions:

- by modeling the design parameters and operating modes, improvement the micro-hydro power plants design operating in low-pressure water flow, it is possible to increase the efficiency of using low-pressure water energy systems.

- based on mathematical modeling, a micro-hydroelectric power station functional scheme for low-pressure watercourses was developed. As a result, a micro hydro power plant was developed for low-pressure watercourses.

- an improved model of a micro-hydroelectric power station for low-pressure watercourses was developed and tested under laboratory conditions. A theoretically grounded experimental sample of the micro-hydroelectric power station was developed and created as a result of the structure and devices simulation.

- ensured the compact design and convenience for developed device applications. As a result, the opportunity to reduce costs in the development and exploitation of micro hydroelectric power station is achieved.

\section{References}

1. REN21 2017. Renewables Global Status Report. Renewable Energy Policy Network for the 21st Century, (2016)

2. http://www.apie.com.ar/Boletines/boletin-27/oferta-hidro.html.

3. V. Schnitzer, Micro hydro power, GTZ, Germany, pp.118 (2009)

4. A. Ihrenberger, K. Lothar, Water wheel turbine for water power stations, Patent, US 6210113B1, USA, (2001) 
5. S. Slavchev, Waterwheel power generating device, Patent, US6534881B1, USA, (2003)

6. V. Krizik, M. Slovakia, Water wheel motor, Patent, US20060245919A1, USA, (2006)

7. G.A. Ibrahim, C.H. Haron, C.H. Azhari, Traditional Water Wheels as a Renewable Rural Energy, J. Power and Energy Engineering, 1, pp. 62-66 (2015)

8. F. Weichbrodt, S. Dimke, J. Hadler, P. Fröhle, Großmaßstäbliche Modellversuche mit einemschwimmenden Energiewandler, Dresdner Wasserbaukolloquium Wasserkraft mehrWirkungsgrad mehrÖkologie mehrZukunft, pp.291-299 (2011)

9. G. Müller, C.Wolter, The breastshot water wheel: design and model tests, Proc. ICE Eng. Sustain Ability, 157 (2004) $203-212$

10. L. Sule, I.N.G. Wardana, R. Soenoko, S.W. Angled, Curved Blades of Deep-Water Wheel Efficiency, Australian Journal of Basic and Applied Sciences, 8 (2014) 186192

11. Y.Yassi, Experimental Study of a High Speed Micro Waterwheel, Iranian Journal of Mechanical Engineering, 14 (2013) 33-47

12. L. Jasa, A. Priyadi, M.H. Purnomo, An Alternative Model of Overshot Waterwheel Based on a Tracking Nozzle Angle Technique for Hydropower Converter, International Journal of Renewable Energy Research, 4 (2014)

13. M. Denny, The efficiency of overshot and undershot waterwheels, Eur. J. Phys. 25 (2004) 193-202

14. G. Müller, K. Kauppert, Performance characteristics of water wheels, J. Hydraul. Res., 42 (2004) 451-460

15. L. Jasa, A. Priyadi, M.H. Purnomo, An Alternative Model of Overshot Waterwheel Based on a Tracking Nozzle Angle Technique for Hydropower Converter, International Journal of Renewable Energy Research, 4 (2014)

16. V.N. Yurenkov, V.M. Ivanov, G.O. Kleyn, A.A. Blinov, T.Yu. Rodivilina, P.V. Ivanova, Calculations methods of waterwheel blade flow, BULLETIN AltSTU. I.I. Polzunova, 2 (2006) 143-150.

17. M. Denny, The efficiency of overshot and undershot waterwheels, Eur. J. Phys. 25 (2004) 193-202

18. G. Müller, K. Kauppert, Performance characteristics of water wheels, J. Hydraul. Res., 42 (2004) 451-460 